\title{
Correction to: Mass coral bleaching of $P$. versipora in Sydney Harbour driven by the 2015-2016 heatwave
}

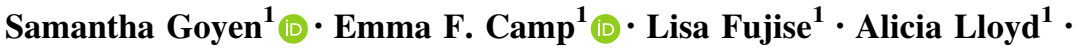 \\ Matthew R. Nitschke ${ }^{1,2}$ (D) Todd C. LaJeunesse ${ }^{3} \cdot$ Tim Kahlke $^{1} \cdot$ Peter J. Ralph $^{1}$ • \\ David Suggett ${ }^{1}$ (D)
}

Published online: 16 April 2019

(C) Springer-Verlag GmbH Germany, part of Springer Nature 2019

Correction to: Coral Reefs

https://doi.org/10.1007/s00338-019-01797-6

Co-author name was misspelt and should read as Todd C.

LaJeunesse.

Publisher's Note Springer Nature remains neutral with regard to jurisdictional claims in published maps and institutional affiliations.

The original article can be found online at https://doi.org/10.1007/s00338-019-01797-6.

Samantha Goyen

Samantha.Goyen@student.uts.edu.au

1 Climate Change Cluster, University of Technology Sydney, Broadway, Ultimo, NSW 2007, Australia

2 Centre for Environmental and Marine Studies, University of Aveiro, Aveiro, Portugal

3 Department of Biology, The Pennsylvania State University, 208 Mueller Laboratory, University Park, PA 16802, USA 